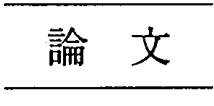

\title{
The Size-Dependence curve as a generalized Competition-Density curve
}

\begin{abstract}
Akio HAGIHARA *
Haglhara, Akio: The Size-Dependence curve as a generalized Competition-Density curve. Jpn. J. For. Plann. $24: 15 \sim 23,1995$ The curve given by the generalized power equation, which has been successfully applied to describe relationships between tree functional amounts and tree size, maintained its shape when plotted on logarithmic coordinates for a fixed exponent value regardless of two other coefficient values. It was found that the generalized power equation belonged to a specified tribe of curves, recognized as a generalization of the well-known Competition-Density curve. The generalized CompetitionDensity curve is newly abbreviated in this paper as the Size-Dependence curve. The Size-Dependence curve includes OGAWA's Relative-Growth curve as a special case. Explicit formulae of the eight different Size-Dependence curve types were systematically represented. The eight different Size-Dependence curve types were united together by appropriately inverting on logarithmic coordinates. A graphic method for obtaining the SizeDependence curve coefficient values was proposed.

萩原秋男：一般化された CーD曲線としてのSーD曲線 森林計画誌 $24: 15 \sim 23$, 1995 樹木個体機能量の樹木サイズへの依存性を定式化するために提案された拡張され たべキ関数が示す両対数軸上での曲線は, ベキ指数の值が一定の場合, 他の 2 つの係数の 值に無関係に一定の形状を保った。この曲線は S - D 曲線と名付けられた曲線群の一つに 属していた， $\mathrm{S}-\mathrm{D}$ 曲線は良く知られた $\mathrm{C}-\mathrm{D}$ 曲線の搪張さ机たものであり，また $\mathrm{R}-\mathrm{G}$ 曲線をも含む曲線群であった， S-D曲線は 8 種類の異なるタイプの曲線群から成り，そ の全てが両対数軸上での平行移動や回転により一つに合体されるという特徵を有してい た. $\mathrm{S}$ 一D曲線を観測値に当てはめる際の係数の求め方が提案された.
\end{abstract}

\section{I . Introduction}

Ninomiya and Hozumi (1983 a, $1983 \mathrm{~b})$ proposed a generalized power equation to describe the dependence of the respiration rate of individual trees on characteristics of their size, such as stem diameter at breast height, stem volume, and phytomass. In self-thinning plantations, the generalized power function has been acknowledged as useful in analyzing the tree size dependences of functional amounts such as phytomass increment (NinOmiYa et al., 1983), photosynthesis (MORI and Hagrhara, 1991 ; YоKOTA and Hagrhara, 1993), and respiration (YоKOTA and HAGIHARA, 1993 ; YСKOTA et al., 1994).

Alternatively, SHINOzAKI and KIRA (1961) proposed the Competition-Density (C-D) curve, which has seen broad, successful forest ecological applications like analyzing the time trajectory of mean stem volume to tree density in self-thinning plantations ( $\mathrm{T}_{\text {ADAKI}}, 1963$ ) ; the allometric relationship between different tree dimensions (OGAWA et al., 1965) ; the relationship between the respiration rate per unit of phytomass and the diameter of woody organs (YODA et al., 1965 ; YoDA, 1983); the frequency distribution of the phytomass of individual trees in forest stands (HozumI et al., 1968; Hozumi, 1971); the regular changes of

*Sch. of Agric. Sci., Nagoya Univ., Nagoya 464-01 名古屋大学農学部 
leaf characteristics such as photosynthetic rate (Hozumi and Kirita, 1970), respiratory rate (Hozumi et al., 1972 ; Hagihara and HozUmi, 1977), chlorophyll content (KIRITA and HozUmi, 1973), and specific leaf area (KURACH et al., 1984) along a radiation gradient through forest canopies; the stratification of forest stands (Hozumi, 1975); the interrelationship among respiration, biomass, and biomass increment (HAGIHARA and Hozumi, 1983; NinomiYa and Hozumi, 1983b); the chemical reaction of anthracene-ethyl alcohol solution (MORI et al., 1983), and the vertical distribution of foliage area (HAGIHARA and HozUmi, 1986). This paper reports aspects of a fourfold investigation, dealing first with peculiar properties of the generalized power function proposed by NinomiYa and Hozumi (1983 a, 1983 b). Second, the generalized power equation is shown to belong to a specified tribe of curves (subsequently called "curve tribe" or "tribe"), recognized as a generalization of the C-D curve proposed by SHINOZAKI and KIRA (1961). The tribe is newly named here as the Size-Dependence (S-D) curve of tree functions. Third, eight different types of the S-D curve are represented and discussed. Finally, a method for obtaining S-D curve coefficient values is discussed.

\section{Generalized Power Equation}

Ninomiya and Hozumi (1983 a, 1983 b) proposed a generalized power equation to describe the dependence of the respiration rate $y$ on the body size characteristic $x$, such as stem diameter at breast height, stem volume or phytomass of individual trees :

$$
y=g\left(x-x_{\min }\right)^{h},
$$

where $g, h$, and $x_{\min }$ are coefficients. Figure 1 illustrates an example depicting the relationship between the aerial respiration $y$ of individual trees and their foliage mass $x$ in a young hinoki (Chamaecyparis obtusa (SiEB. et $Z_{\mathrm{UCC}}$.) E $\mathrm{EDL}_{\mathrm{ND}}$.) stand

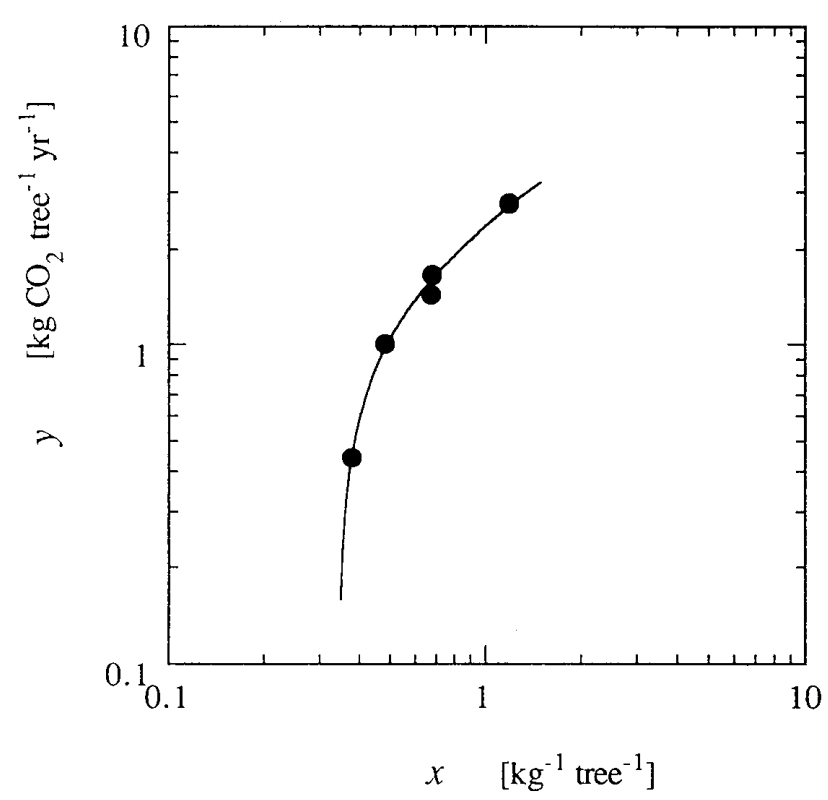

Fig. 1. The Size-Dependence curve* used to describe the tree size dependence of a whole-tree function.

* Based on equation (1), where $y$ and $x$, respectively, represent the annual aerial respiration and the foliage mass of individual trees in a Chamaecyparis obtusa plantation (Yокота et al., 1994).

(YокотA et al., 1994).

Biologically, equation (1) means that as the body size $x$ approaches its critical size $x_{\min }$, below which trees cannot survive in the forest stand, the respiration rate $y$ drops abruptly. However, the relationship satisfies the following equation in the range where the body size $x$ is sufficiently larger than $x_{\min }$ :

$$
y=g x^{h} .
$$

It is well-known that the relationship between an animal's characteristic $y$ and its body size $x$ usually takes the form of equation (2), called a power formula because the dependent variable $y$ changes as some power $h$ of the independent variable $x$ (Peters, 1983). Likewise, Hozumi and Shinozaki (1974) designated any functional amount per individual tree $y$ satisfying equation (2) as one belonging to the allometric tribe with respect to the body size $x$. 
Hereafter, as proposed in this paper, the $\ln y$-ln $x$ curve, such as Figure 1, given by the generalized power function (equation 1), is called the S-D curve of tree functions.

\section{Competition-Density Curve}

SHINOZAKI and KIRA (1956) proposed the logistic theory describing the effect of plant density on average phytomass in higher plants, i. e., the Competion-Density effect. The theory expresses the average phytomass $y$ as a function of the plant density $x$ as follows :

$$
\frac{1}{y}=A x+B,
$$

where $A$ and $B$ are determined at each growth stage and, thus, functions of time. The $y$ to $x$ curve given by equation (3) when plotted on logarithmic coordinates inherently keeps its shape despite changes in the $A$ - and $B$-value. Furthermore, SHINOZAKI and KIRA (1961) concluded that even when $x$ (or $y$ ) is replaced by $1 / x$ (or $1 / y$ ) in equation (3), no modifications are necessary in mathematical formulations. Therefore, the $y$ to $x$ relation can represent four different curve types. Yet another four types of $y$ to $x$ relationships develop by exchanging $x$ and $y$ for each other in each of the previous four $y$ to $x$ relationships. The resulting curve tribe, including the eight types of $y$ to $x$ relationships on logarithmic coordinates, was called the C-D curve by SHINOZAKI and KIRA (1961).

\section{N. Properties of the Size-Dependence Curve}

Following SHINOZAKI and KIRA's (1961) mathematical manipulation for the $C-D$ curve, the specific properties of the S-D curve, given by equation (1) when plotted on logarithmic coordinates, are examined below. A simple case is introduced where both values of $g$ and $x_{\min }$ (equation 1 ) equal one, and generate a normalized form of equation (1), i. e.,

$$
y=(x-1)^{h} .
$$

In the $\ln y-\ln x$ curve given by equation (4), if we set

$$
\begin{aligned}
& y=\exp \eta \quad(\text { or } \ln y=\eta) \\
& x=\exp \xi \quad(\text { or } \ln x=\xi),
\end{aligned}
$$

then equation (4) reduces to

$$
\exp \eta=(\exp \xi-1)^{h}
$$

depicting the equation (4) S-D curve when plotted on logarithmic coordinates.

Next, considering equation (5) with

$$
\begin{aligned}
& g=\exp \alpha \quad(\text { or } \ln g=\alpha) \\
& \quad \text { and } \\
& x_{\min }=\exp \beta \quad\left(\text { or } \ln x_{\min }=\beta\right),
\end{aligned}
$$

then equation (1) reduces to

$$
\exp (\eta-\alpha-h \beta)=(\exp (\xi-\beta)-1)^{h}
$$

depicting the equation (1) S-D curve when plotted on logarithmic coordinates. Now, setting

$$
\begin{aligned}
& \eta^{\prime}=\eta-(\alpha+h \beta) \\
& \xi^{\prime}=\xi-\beta \\
& \text { transforms equation }(8) \text { into } \\
& \quad \exp \eta^{\prime}=\left(\exp \xi^{\prime}-1\right)^{h} .
\end{aligned}
$$

Equation (10) is obviously the same mathematical form as equation (6). Substituting $(\eta, \xi)$ for $(\eta$, $\left.\xi^{\prime}\right)$ in equation (10) merely causes parallel displacement of the coordinate axes (see Figure 2). Therefore, changes of the $g$ - and $x_{\min }$-value will never alter the S-D curve's shape. Any two S-D curves whose $g^{-}$and $x_{\min }$-values are different, can always be united by appropriate parallel shifting of the coordinates axes.

The S-D curve shape is characterized by the following properties. When

$$
x=x_{\min }
$$

in equation (1), $y$ tends to zero. Drawing from equations (5) and (7) allows equation (11) to become

$$
\xi=\beta,
$$

which depicts a vertical line on logarithmic coordinates. However, when $x$ is large, compared to $x_{\min }$ in equation (1), equation (1) exactly duplicates equation (2) which becomes 


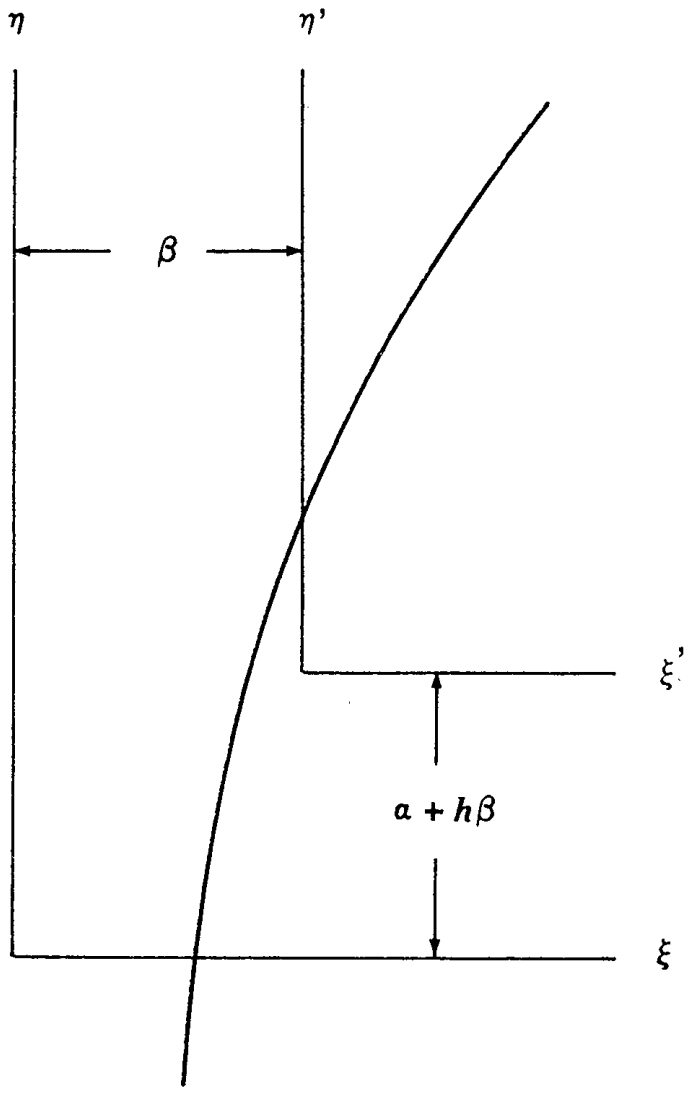

Fig. 2. The Size-Dependence curve on the $\eta-\xi$ or the $\eta^{\prime}-\xi^{\prime}$ coordinates. *

* The S-D curve on the $\eta-\xi$ coordinates is given by equation (1), while the S-D curve on the $\eta^{\prime}-\xi^{\prime}$ coordinates is given by equation (4).

$$
\eta=\alpha+h \xi,
$$

also depicting a straight line with slope $h$ on logarithmic coordinates. Figure 3 shows that the two straight lines given by equations (12) and (13) represent asymptotes of the $S-D$ curve.

Equation (13) tells that the S-D curve rises at the right tail as the $h$-value increases. Figure 4 shows the change in shape of the $S-D$ curve given by the normalized equation (4) with changing values of $h$.

\section{$\mathrm{V}$. Estimating Coefficient Values of the Size-Dependence Curve}

The asymptotes intersection point, $\mathrm{P}$ in Figure 3 , as specified by equations (12) and (13), is given by $x_{\mathrm{P}}=x_{\min }$

and

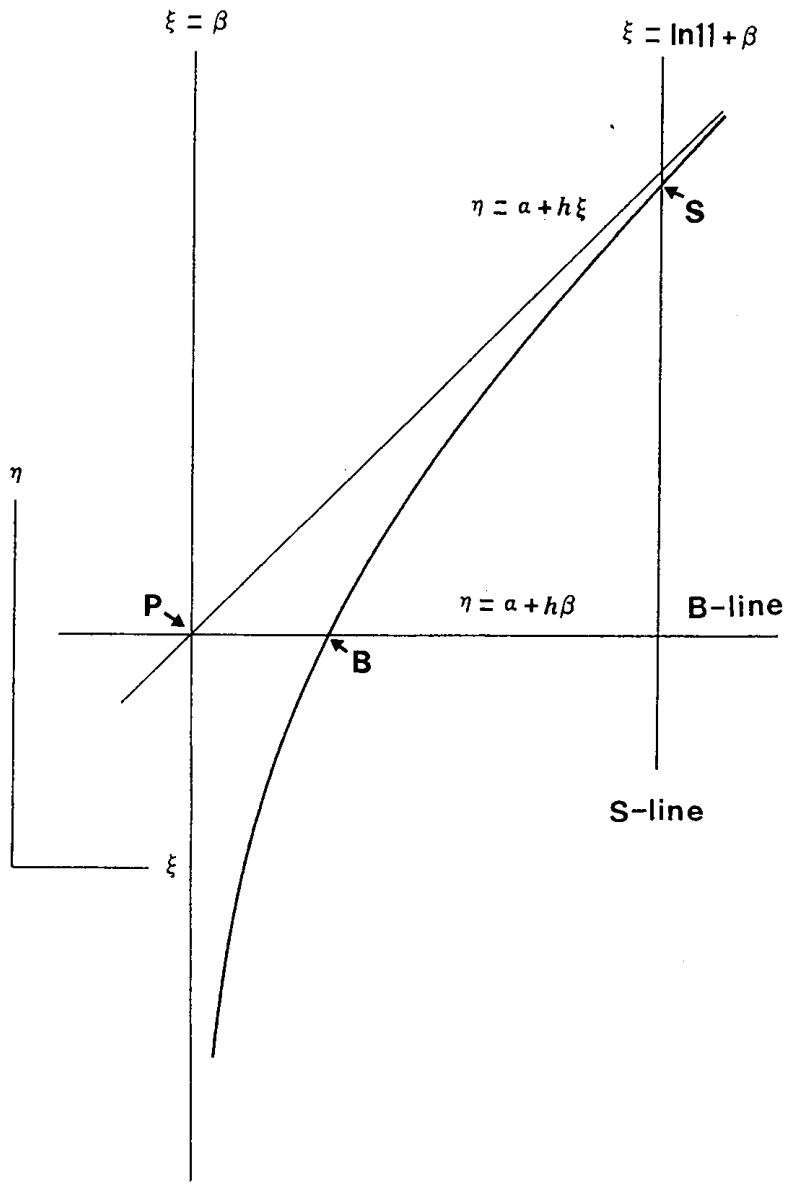

Fig. 3. Fundamental elements of the SizeDependence curve. ${ }^{*}$

${ }^{*}$ Two asymptotes $(\eta=\beta$ and $\eta=\alpha+h \xi)$, $\mathrm{B}$-line $(\eta=\alpha+h \beta)$, and $\mathrm{S}$-line $(\xi=\ln 11+\beta)$, and $\mathrm{P}, \mathrm{B}$, and $\mathrm{S}$ points of the $\mathrm{S}-\mathrm{D}$ curve.

$$
y_{\mathrm{P}}=g x_{\min }{ }^{h} \text {. }
$$

Point B, another important fixed point, exists at the intersection between the S-D curve and the line $(\eta=\alpha+h \beta$ in Figure 3 or the B-line in Figure 4) passing through point P. Point B's coordinates are

$$
\begin{aligned}
& x_{\mathrm{B}}=2 x_{\min } \\
& y_{\mathrm{B}}\left(=y_{\mathrm{P}}\right)=g x_{\min }{ }^{n} .
\end{aligned}
$$

Note that the distance between the two points $\mathrm{P}$ and $\mathrm{B}$ is always $\ln 2$ regardless of the $h$-value. Furthermore, another fixed point $S$ is defined as the intersection of the S-D curve and the line $(\xi=$ $\ln 11+\beta$ in Figure 3 or the $S$-line in Figure 4) 


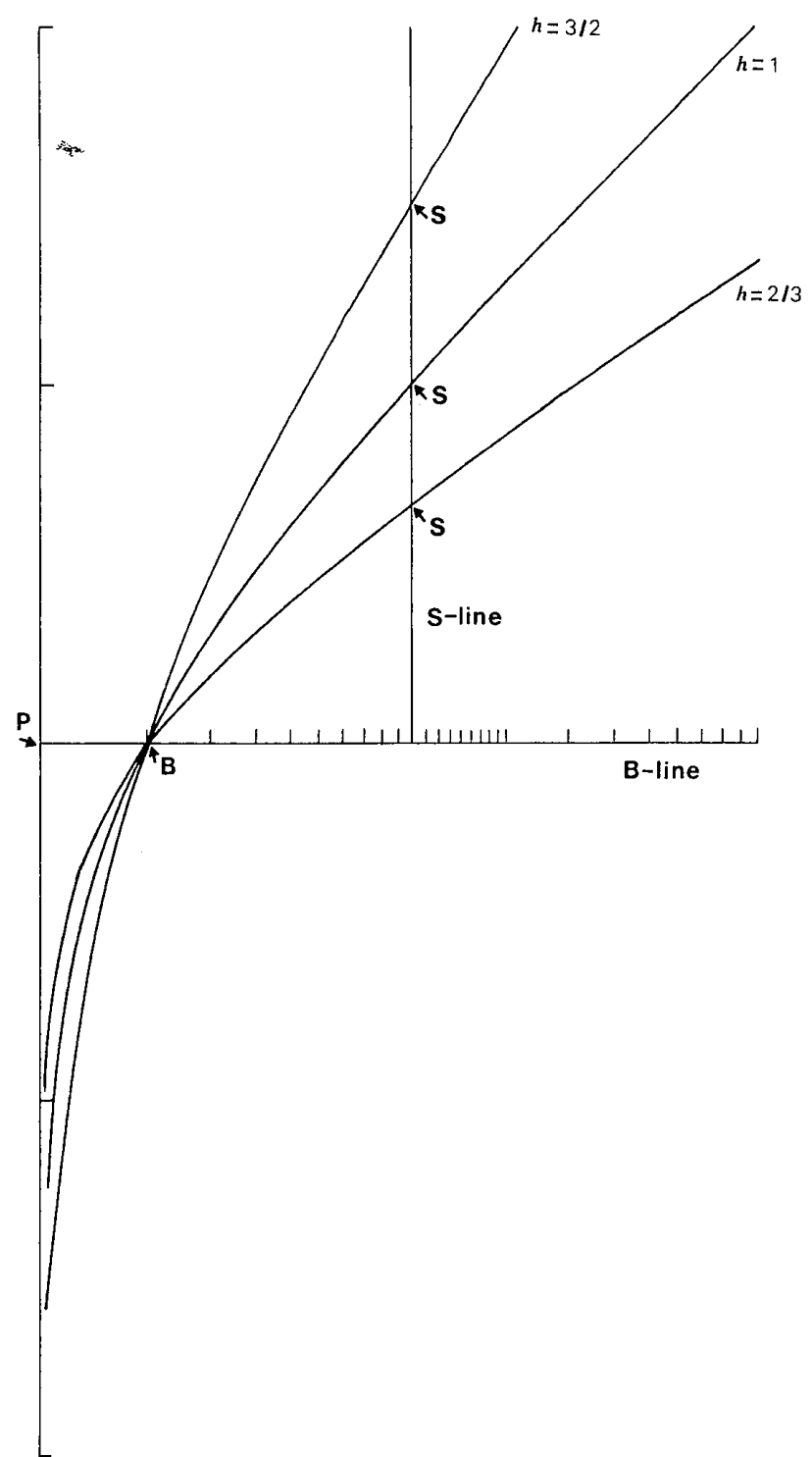

Fig. 4. Changes * in the shape of the SizeDependence curve.

* Given by equation (4) with the value of $h$.

perpendicular to the $\mathrm{B}$-line. The coordinates of point $S$ are

$$
\begin{aligned}
& x_{\mathrm{S}}=11 x_{\min } \\
& y_{\mathrm{S}}=10^{h} y_{\mathrm{B}} .
\end{aligned}
$$$$
\text { and }
$$

Knowing the coordinates of points $B$ and $S$ allows tentative evaluation of the values of $x_{\min }, h$, and $g$ (equations 15 and 16) which are given by

$$
\begin{aligned}
& x_{\min }=\frac{x_{\mathrm{B}}}{2}, \\
& h=\log \left(\frac{y_{\mathrm{S}}}{y_{B}}\right),
\end{aligned}
$$

and

$$
g=\frac{y_{\mathrm{B}}}{x_{\min }{ }^{h}}
$$

\section{The Size-Dependence Curve Tribe}

Even when $x$ (or $y$ ) is replaced with $1 / x$ (or $1 / y)$ in equation (1), no modifications are necessary, just as with the C-D curve derivation (SHINOZAKI and KIRA, 1961). Similarly, the S-D curve tribe can be represented by the following four types of $y$ to $x$ relationships :
I ) $y=g\left(x-x_{\min }\right)^{n}$,
II) $y=g\left(\frac{1}{x}-\frac{1}{x_{\max }}\right)^{n}$,
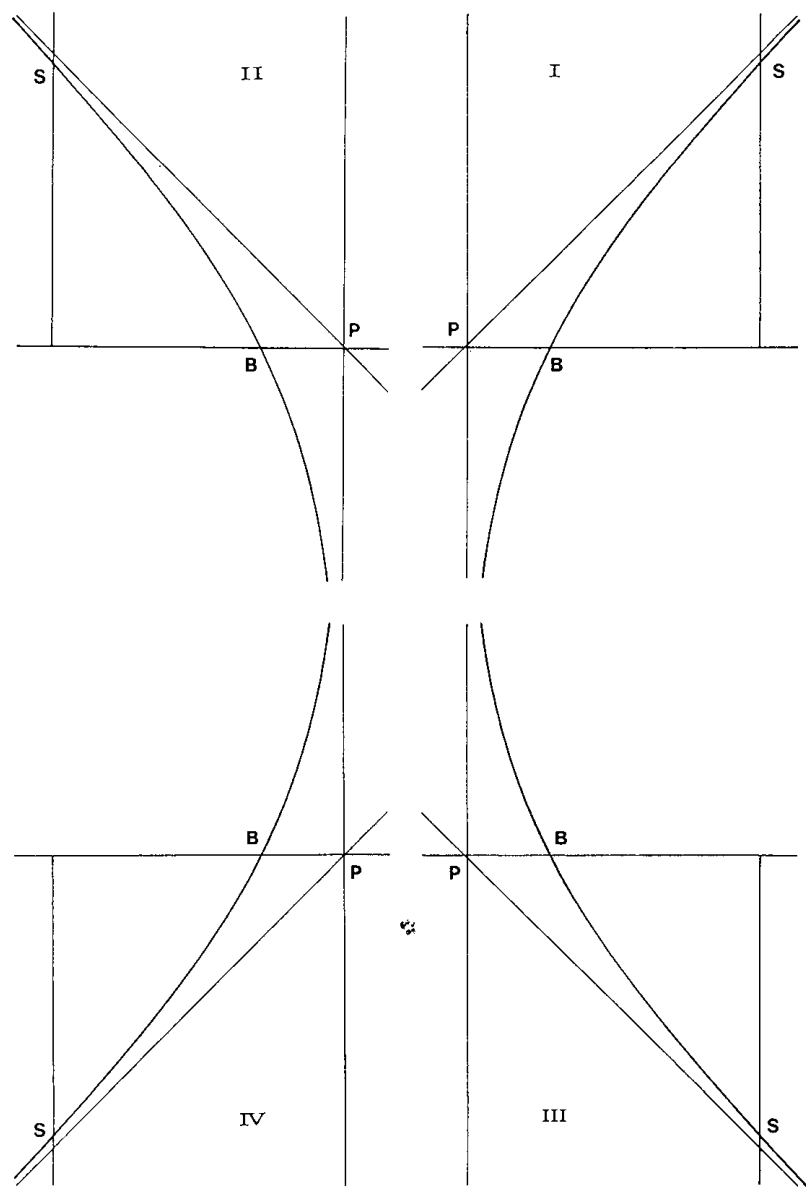

Fig. 5. Types I to IV (equation 18) of the SizeDependence curve.*

* This group is characterized by the horizontal position of the B-line. 
III) $\frac{1}{y}=g\left(x-x_{\min }\right)^{n}$,

and

IV) $\frac{1}{y}=g\left(\frac{1}{x}-\frac{1}{x_{\max }}\right)^{h}$,

where $x_{\min }$ and $x_{\max }$ represent the minimum and the maximum $x$-value, respectively. The four S-D curve types are united by an appropriate inversion with respect to an abscissa or an ordinate axis on logarithmic coordinates. As shown in Figure 5 , this group is characterized by the horizontal position of the B-line. When $h$ in equation (18) is equal to one, equation (18) becomes identical with the second group of the $C-D$ curve tribe proposed by SHINOzAKI and KIRA (1961).

Four additional S-D curve types are introduced as follows :
V) $y=g x^{h}+y_{\min }$,
VI) $y=\frac{1}{g x^{h}}+y_{\min }$
VII) $\frac{1}{y}=g x^{h}+\frac{1}{y_{\max }}$, and
VIII) $\frac{1}{y}=\frac{1}{g x^{h}}+\frac{1}{y_{\max }}$;

where $y_{\min }$ and $y_{\max }$ represent the minimum and the maximum $y$-value, respectively. Type $\mathrm{V}$ can be obtained by exchanging $x$ and $y$ for each other in Type I. Similar correspondence exists between Types II and VI, Types III and VII, and Types IV and VIII. The four S-D curve types in equation (19) are united by being correctly rotated on logarithmic coordinates. Types $\mathrm{V}$ to VIII form a group whose B-line is vertical (Figure 6). When $h$ in equation (19) is equal to one, equation (19) becomes identical with the first $C-D$ curve group proposed by ShINOZAKI and KIRA (1961). Figure 7 describes the interrelationships between $S-D$ curve types.

OGAWA et al. (1965) found that the allometric relationship between different tree dimensions could be fairly well described by a generalized allometric function given by equation Type VIII. OGAWA (1980) further proposed the RelativeGrowth $(R-G)$ curve tribe given by equation Types $\mathrm{V}$ to VIII, which includes the generalized allometric function (Type VIII) as a special case. As a result, the generalized allometric function is included in the $R-G$ curve tribe (equation 19),
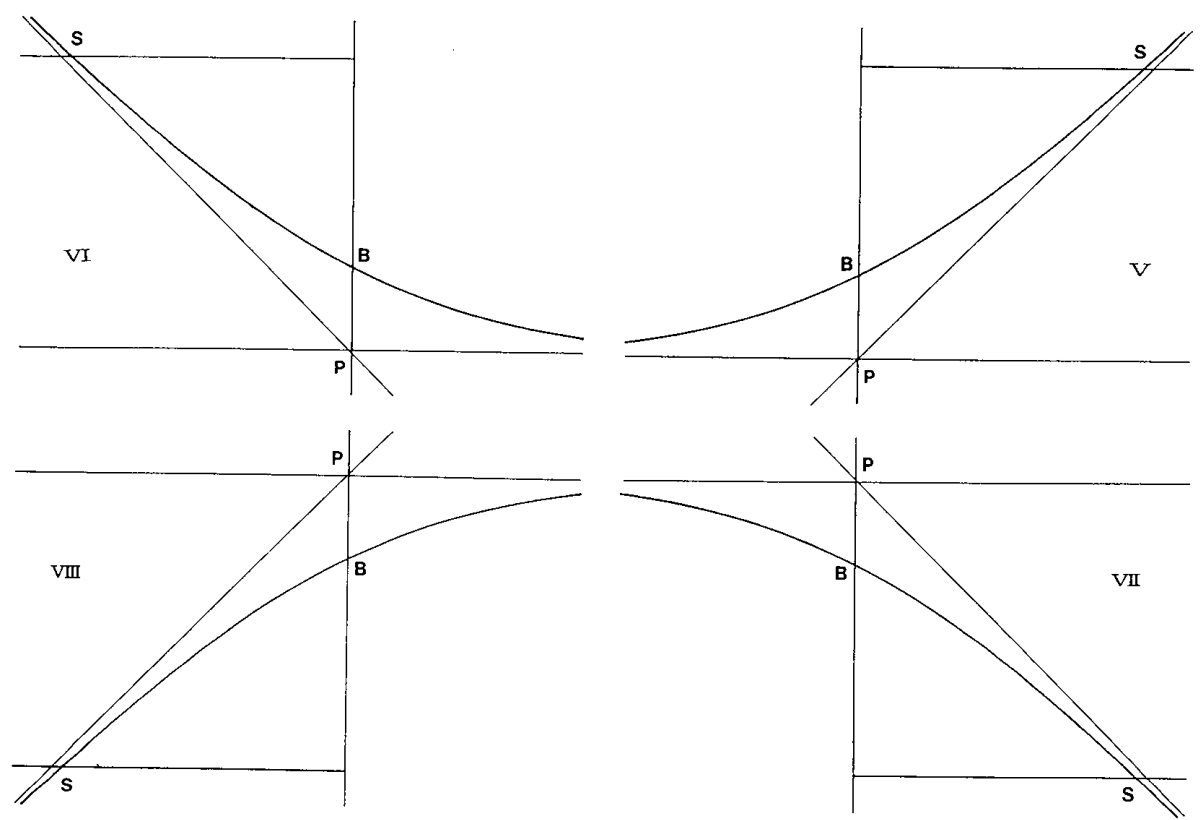

Fig. 6. Types V to VIII (equation 19) of the Size-Dependence curve. ${ }^{*}$ * This group is characterized by the vertical position of the B-line. 


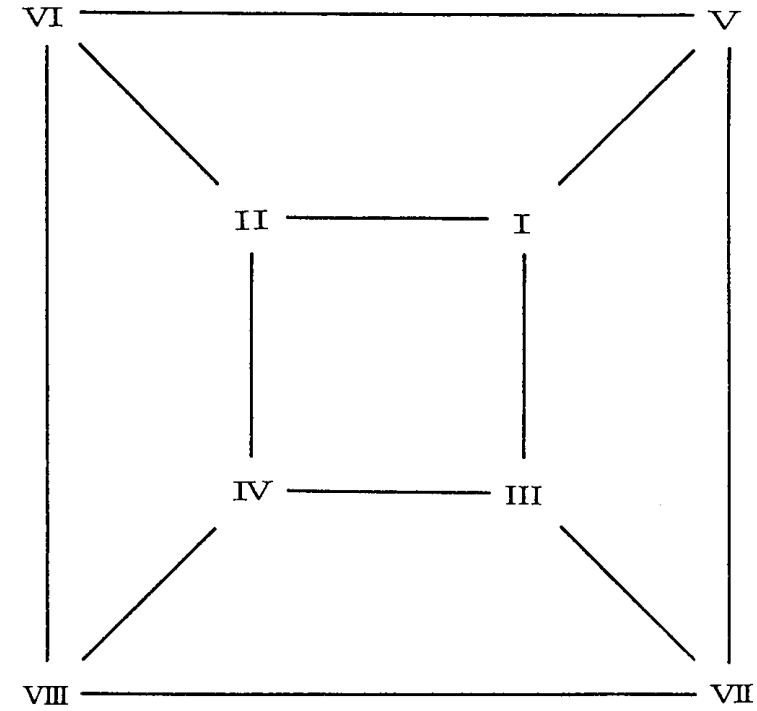

Fig. 7. Interrelationships between types of the Size-Dependence curve. ${ }^{*}$

* The types connected with the horizontal, the vertical, and the diagonal lines are symmetrical with respect to an abscissa axis, an ordinate axis, and a straight line with an inclination of $45^{\circ}$ (or $-45^{\circ}$ ) on logarithmic coordinates, respectively. which in turn can be included in the S-D curve tribe (equations 18 and 19).

Table 1 summarizes cardinal values of the $S-D$ curve tribe. The tentatively estimated values of the coefficients $x_{\min }\left(x_{\max }, y_{\min }\right.$ or $\left.y_{\max }\right), h$, and $g$ may serve as initial values for the least squares method of nonlinear regression. Biological data tend to show the relative rather than the absolute error. The relative error of the variable $y$ is shown by a zone of constant width on the ordinate axis along the S-D curve on logarithmic coordinates. This is of great advantage for graphically assessing coefficient values on logarithmic coordinates.

\section{Acknowledgments}

I gratefully acknowledge valuable suggestions by Prof. Emeritus K. Hozumi in preparing this manuscript. This study was partially funded by a Grant-in-Aid for Scientific Research (No. 05556023) from the Ministry of Education, Science and Culture, Japan.

Table 1. Cardinal values of the S-D curve.

\begin{tabular}{|c|c|c|c|c|}
\hline Type & $y-x$ & $\begin{array}{ll}x_{\min }, & x_{\max } \\
y_{\min }, & y_{\max }\end{array}$ & $h$ & $g$ \\
\hline I & $y=g\left(x-x_{\mathrm{min}}\right)^{b}$ & $x_{\mathrm{B}} / 2$ & $\log \left(y_{S} / y_{B}\right)$ & $y_{B} / x_{m 1 n}{ }^{A}$ \\
\hline II & $y=g\left(1 / x-1 / x_{\max }\right)^{h}$ & $2 x_{\mathrm{B}}$ & $\log \left(y_{S} / y_{B}\right)$ & $y_{\mathrm{B}} x_{\max }{ }^{h}$ \\
\hline III & $1 / y=g\left(x-x_{\min }\right)^{b}$ & $x_{\mathrm{B}} / 2$ & $\log \left(y_{B} / y_{S}\right)$ & $1 /\left(y_{\mathrm{B}} x_{\mathrm{m} 1 \mathrm{n}}{ }^{b}\right)$ \\
\hline IV & $1 / y=g\left(1 / x-1 / x_{\max }\right)^{b}$ & $2 \pi_{\mathrm{B}}$ & $\log \left(y_{B} / y_{S}\right)$ & $x_{\max }{ }^{3} / y_{B}$ \\
\hline V & $y=g x^{a}+y_{\mathrm{m} 1 \mathrm{n}}$ & $y_{\mathrm{B}} / 2$ & $\log \left(x_{B} / x_{S}\right)$ & $y_{\mathrm{m} 1 \mathrm{n}} / x_{\mathrm{B}}$ \\
\hline VI & $y=1 /\left(g x^{b}\right)+y_{m i n}$ & $y_{\mathrm{B}} / 2$ & $\log \left(x_{\mathrm{S}} / x_{\mathrm{B}}\right)$ & $1 /\left(y_{\mathrm{m} \perp \mathrm{n}} x_{\mathrm{B}}{ }^{b}\right)$ \\
\hline VII & $1 / y=g x^{b}+1 / y_{\max }$ & $2 y_{B}$ & $\log \left(x_{\mathrm{B}} / x_{\mathrm{S}}\right)$ & $1 /\left(y_{\mathrm{ma}} x_{\mathrm{B}}{ }^{b}\right)$ \\
\hline VIII & $1 / y=1 /\left(g x^{b}\right)+1 / y_{\max }$ & $2 y_{B}$ & $\log \left(x_{S} / x_{B}\right)$ & $y_{\max } / x_{\mathrm{B}}{ }^{b}$ \\
\hline
\end{tabular}

$\left(x_{\mathrm{B}}, y_{\mathrm{B}}\right)$, coordinate of $\mathrm{B}$-point; $\left(x_{\mathrm{B}}, y_{\mathrm{B}}\right)$, coordinate of the $\mathrm{S}-$ point. Concerning the $\mathrm{B}-$ and $\mathrm{S}-$ point, see Figure 3. 


\section{Literature cited}

(1) Hagrihara, A. and Hozumi, K. (1977) Estimation of canopy respiration and its seasonal change in a Chamaecyparis obtusa plantation. J. Jpn. For. Soc. $59: 405 \sim 413$.

(2) Hagihara, A. and Hozumi, K. (1983) Studies on the primary production in a Chamaecyparis obtusa plantation. J. Jpn. For. Soc. 65 : $357 \sim 365$.

(3) Hagihara, A. and Hozumi, K. (1986) An estimate of the photosynthetic production of individual trees in a Chamaecyparis obtusa plantation. Tree Physiol. 1:9 20.

(4) Hozumi, K. (1971) Studies on the frequency distribution of the weight of individual trees in a forest stand. III. A beta-type distribution. Jpn. J. Ecol. 21 : 152 167.

(5) Hozumi, K. (1975) Studies on the frequency distribution of the weight of individual trees in a forest stand. V. The $M-w$ diagram for various types of forest stands. Jpn. J. Ecol. $25: 123 \sim 131$.

(6) Hozumi, K., Kirita, H. and NishioKa, M. (1972) Estimation of canopy photosynthesis and its seasonal change in a warmtemperate evergreen oak forest at Minamata (Japan). Photosynthetica $6: 158 \sim 168$.

( 7 ) Hozumi, K. and KIRITA, H. (1970) Estimation of the rate of total photosynthesis in forest canopies. J. Plant Res. 83 : 144 151.

(8) Hozumi, K. and Shinozaki, K. (1974) Studies on the frequency distribution of the weight of individual trees in a forest stand. IV. Estimation of the total function of a forest stand and a generalized mean plant. Jpn. J. Ecol: 24 : $207 \sim 212$.

(9) Hozumi, K., Shinozaki, K. and Tadaki, K. (1968) Studies on the frequency distribution of the weight of individual trees in a forest stand. I. A new approach toward the analysis of the distribution function and the $-3 / 2$ th power distribution. Jpn. J. Ecol. $18: 10 \sim 20$.
(10) Kirita, H. and Hozumi, K. (1973) Estimation of the total chlorophyll amount and its seasonal change in a warm-temperate evergreen oak forest at Minamata, Japan. Jpn. J. Ecol. 23 : 195 200.

(11) Kurachi, N., Haghara, A. and Hozumi, K. (1984) Photosynthetic production in a Larix leptolepis plantation (IV). Photosynthetic characteristics of long and short shoot leaves. Trans. Jpn. For. Soc. Chubu Br. 32 : 131 134. (in Japanese).

(12) Mori, S. and Hagihara, A. (1991) Gross photosynthetic production of individual trees in a Chamaecyparis obtusa plantation. Bull. Nagoya Univ. For. $11: 1-14$.

(13) Mori, S., Kurachi, N., Hagihara, A. and Hozumi, K. (1983) Some discussion on measuring light by an anthracene method. Trans. Jpn. For. Soc. Chubu Br. $31: 99 \sim$ 102. (in Japanese).

(14) Ninomiya, I. and Hozumi, K. (1983 a) Respiration of forest trees. II. Measurement of nighttime respiration in a Chamaecyparis obtusa plantation. J. Jpn. For. Soc. 65 : 193200.

(15) Ninomiya, I. and Hozumi, K. (1983 b) Respiration of forest trees. III. Estimation of community respiration. J. Jpn. For. Soc. 65 : $275 \sim 281$.

(16) Ninomiya, I., Miyaura, T. and Hozumi, K. (1983) Gross production of a 25-year-old Chamaecyparis obtusa S. and $Z$. plantation based on the measurement of individual trees. Trans. Jpn. For. Soc. $94: 355 \sim 356$. (in Japanese).

(17) Ogawa, H. (1980) Structure and Functions of Plant Populations. $221 \mathrm{pp}$, Asakura, Tokyo. (in Japanese).

(18) Ogawa, H., Yoda, K., Ogino, K. and KIRA, T. (1965) Comparative ecological studies on three main types of forest vegetation in Thailand. II. Plant biomass. Nature \& Life in SE Asia $4: 49 \sim 80$.

(19) Peters, R. H. (1983) The Ecological Implica- 
tions of Body Sizes. $329 \mathrm{pp}$, Cambridge Univ. Press, Cambridge.

(20) SHINOZAKI, K. and KIRA, T. (1956) Intraspecific competition among higher plants. VII. Logistic theory of the C-D effect. J. Inst. Polytech. Osaka City Univ. D $7: 35 \sim 72$.

(21) Shinozaki, K. and Kira, T. (1961) The C-D rule, its theory and practical uses. J. Biol. Osaka City Univ. $12: 69 \sim 82$.

(22) TADAKI, Y. (1963) The pre-estimating of stem yield based on the competitiondensity effect. Bull. For. Forest Prod. Res. Inst. $154: 1 \sim 19$. (in Japanese with English summary).

(23) YoDA, K. (1983) Community respiration in a lowland rain forest in Pasoh, Peninsular Malaysia. Jpn. J. Ecol. $33: 183 \sim 197$.
(24) Yoda, K., Shinozaki, K., Ogawa, H., Hozumi, K. and KIRA, T. (1965) Estimation of the total amount of respiration in woody organs of trees and forest communities. J. Biol. Osaka City Univ. $16: 15-26$.

(25) Yokota, T. and Hagihara, A. (1993) Size dependence of the $\mathrm{CO}_{2}$ gas-exchange of individual hinoki (Chamaecyparis obtusa (Sieb. et Zucc.) Endl.) trees. Annual $\mathrm{CO}_{2}$ gas-exchange. Trans. Jpn. For. Soc. 104 : 515 518. (in Japanese).

(26) Yokota, T., Ogawa, K. and Hagihara, A. (1994) Dependence of the aboveground respiration of hinoki cypress (Chamaecyparis obtusa) on tree size. Tree Physiol. 14:467 $\sim 479$.

(Received June 14, 1994) 